\title{
Occupational exposure to polychlorinated dibenzo-p-dioxins and dibenzofurans in a magnesium production plant
}

\author{
Marianne Hansson, Terje Grimstad, Christoffer Rappe
}

\begin{abstract}
Objectives-The production of magnesium is a well known source of both aliphatic and aromatic chlorinated compounds, among others the polychlorinated dibenzo-p-dioxins (PCDDs) and polychlorinated dibenzofurans (PCDFs). The aim of this study was to establish whether increased concentrations of PCDDs and PCDFs could be found in the blood of workers in a magnesium plant. Methods-Blood plasma from 10 workers, employed at a magnesium plant for 10 to 36 years, and from a control group consisting of nine people who had no direct contact with the production were studied. Isomer specific analyses of PCDDs and PCDFs by means of high resolution gas chromatography/high resolution mass spectrometry (HRGC/HRMS) techniques were performed.

Results-A significant increase was found in the concentrations of some of the congeners, mainly PCDFs, in the workers compared with the control group. Octachlorodibenzofuran (OCDF) is the congener that most strongly correlates with occupational exposure in the magnesium plant. Low concentrations of $1,2,3,4,6,8,9-h$ htachlorodibenzofuran were found in seven of the workers. Such isomers-that is, not $2,3,7,8$-substitutedare rarely found in human samples.

Conclusion-Due to the long biological half lives and lipid solubility of PCDDs and PCDFs, blood analyses may serve as an index of past cumulative occupational exposure and a means of assessing a person's exposure situation.
\end{abstract}

(Occup Environ Med 1995;52:823-826)

Keywords: dibenzo-p-dioxins; dibenzofurans; occupational exposure

Institute of

Environmental

Chemistry, University

of Umeå, S-901 87

Umeå, Sweden

M Hansson

C Rappe

Health Department, HYDRO Porsgrunn, N3901 Porsgrunn,

Norway

T Grimstad

Correspondence to M Hansson, Institute of Environmental Chemistry, 87 Umeă, Sweden.

Accepted 17 July 1995
Environmental and human exposure to polychlorinated dibenzo-p-dioxins (PCDDs) and polychlorinated dibenzofurans (PCDFs) have been the focus of much attention in recent years. These compounds are persistent and highly lipophilic, they bioaccumulate in the food chain and have been shown to cause a variety of biological and toxic responses including immunological and hepatic toxicity, carcinogenic, and teratogenic effects. ${ }^{12}$ Humans are exposed through the intake of food such as fish, meat, and dairy products, resulting in a general background of PCDDs and PCDFs that is fairly similar throughout the industrialised world. Higher concentra- tions of 2,3,4,7,8-pentachlorodibenzofuran are found in Europe than in the United States. ${ }^{3}$ Human concentrations of PCDDs and PCDFs and major exposure routes are summarised in a review by Ryan and Norstrom. ${ }^{4}$ People exposed accidentally or occupationally often display a different congener pattern than those exposed indirectly through the environment and such exposure can be identified through the analysis of PCDDs and PCDFs in blood. Several occupational studies are focused on exposure to 2,3,7,8-tetrachlorodibenzo-p-dioxin (TCDD), a congener associated with the production and use of phenoxy herbicides. For example, high concentrations of TCDD among chemical workers involved in the production of 2,4,5trichlorophenol have been reported by Patterson et al. ${ }^{5}$ In a Swedish study of production workers who had been employed in a factory producing chlorophenoxy herbicides and chlorophenols, increased concentrations of TCDD and 1,2,3,7,8-pentachlorodibenzop-dioxin were found 16 to 21 years after the workers had left their employment. ${ }^{6}$ Furthermore a study presented by Päpke et al. ${ }^{7}$ showed that various kinds of occupational exposure to PCDDs and PCDFs-for example, in the production of tri and pentachlorophenol and at a metal reclamation plant-resulted in a characteristic congener pattern in blood.

Significant amounts of PCDDs and PCDFs are formed as undesired byproducts in various industrial and high temperature processes. ${ }^{8}$ Magnesium production involves several different steps and it is in the chlorination and electrolytic processes that different organic chlorocompounds are formed-for example, considerable amounts of PCDDs and PCDFs. ${ }^{9}$ These compounds have been detected in effluents and exhausts from a magnesium plant at Porsgrunn in the southern part of Norway, as well as in sediment samples and marine biota collected in the vicinity of the plant. The yearly emission to the waste water from the plant has been estimated at $0.3-0.5 \mathrm{~kg}$ TCDD equivalents ${ }^{10-12}$ calculated according to the Nordic model, ${ }^{2}$ and the concentration ratio of $\Sigma \mathrm{PCDF} / \Sigma \mathrm{PCDD}$ is about 10:1. In a study of human milk from Scandinavia, the concentration of PCDFs was found to be slightly higher in the SkienPorsgrunn area, where the magnesium plant is located, than in other regions in Norway. ${ }^{13}$ As well as organic chlorocompounds, the production of magnesium involves combined occupational exposure to many other potentially harmful substances such as asbestos (before 1980), chlorine gas, and hydrochloric 
aerosols. Strong magnetic fields are also present in the work environment. A higher incidence of different types of cancers in a cohort of magnesium production workers was found in a study by Heldas et $\mathrm{al}^{14}$ in which the relation between exposure to factors in the working environment and the development of cancer is discussed. Since 1990, there has been a considerable reduction in emissions from the plant. The primary aim of this study was to compare the concentrations of PCDDs and PCDFs in the blood lipids of workers in the magnesium plant with those found in controls who had no connection with the production. Moreover, the study was thought to be of importance to ongoing efforts to improve working conditions at the plant.

\begin{abstract}
Method
SUBJECTS

Hexachlorobenzene (HCB) is formed under conditions similar to those under which PCDDs and PCDFs are formed, and is present in emissions from the plant and in the working environment. The health department at the plant has monitored the concentrations of HCB in blood samples from the workers since the mid-1970s. Although HCB has a much shorter biological half life than PCDDs and PCDFs, it was considered a possible indicator of occupational exposure to organic chlorocompounds. The workers with the highest concentrations of hexachlorobenzene (between 21 to $52 \mathrm{ng} / \mathrm{g}$ whole blood) were chosen for this study. They were working either in the electrolytic or the chlorination sector of the plant. Several of the workers had experienced episodes of exposure to chlorine gas resulting in symptoms ranging from minor discomfort to respiratory impairment requiring acute medical treatment. Ten workers, employed for 10 to 36 years, and a control group consisting of nine people working at the same plant were studied. As far as dioxin exposure is concerned, the only difference between the control group and the workers is the fact that the workers are directly involved in the production process. There were two women in each group. The mean age at the time of the study was 48 in the group of work-
\end{abstract}

Table 1 Mean concentrations of PCDFs and PCDDs, expressed in pg/g lipid, in blood plasma from workers and controls

\begin{tabular}{lcccl}
\hline & $\begin{array}{l}\text { Variable } \\
\text { No }\end{array}$ & $\begin{array}{l}\text { Controls }(n=9) \\
\text { mean }(\text { range) }\end{array}$ & $\begin{array}{l}\text { Workers }(n=9) \\
\text { mean (range) }\end{array}$ & $P^{*}$ value \\
\hline PCDFs: & & & & \\
$2,3,7,8-$ TCDF & 1 & $2 \cdot 9(1 \cdot 2-4 \cdot 7)$ & $3 \cdot 5(1 \cdot 5-6 \cdot 1)$ & $0 \cdot 5$ \\
$1,2,3,7,8-P e C D F$ & 2 & $2 \cdot 2(<1-30)$ & $5 \cdot 4(<1-11)$ & $0 \cdot 06$ \\
$2,3,4,7,8-P e C D F$ & 3 & $20(14-29)$ & $51(19-170)$ & $0 \cdot 02$ \\
$1,2,3,4,7,8-H x C D F$ & 4 & $22(5 \cdot 9-94)$ & $59(23-150)$ & $0 \cdot 01$ \\
$1,2,3,6,7,8-H x C D F$ & 5 & $12(5 \cdot 7-31)$ & $59(19-190)$ & $0 \cdot 002$ \\
$2,3,4,6,7,8-H x C D F$ & 6 & $3 \cdot 4(<1-6 \cdot 8)$ & $5 \cdot 4(2-9 \cdot 6)$ & $0 \cdot 09$ \\
$1,2,3,4,6,7,8-H p C D F$ & 7 & $14(4 \cdot 7-32)$ & $85(21-150)$ & $0 \cdot 0007$ \\
$1,2,3,4,7,8,9-H p C D F$ & 8 & $62 \cdot 9(<2-16)$ & $0 \cdot 0005$ \\
OCDF & 9 & $7 \cdot 5(<3-18)$ & $216(17-560)$ & $0 \cdot 0005$ \\
PCDDs: & 10 & $3 \cdot 9(2 \cdot 8-6 \cdot 3)$ & $8 \cdot 2(2 \cdot 5-35)$ & $0 \cdot 1$ \\
$2,3,7,8-$ TCDD & 11 & $7 \cdot 2(5 \cdot 0-13)$ & $16(6 \cdot 7-51)$ & $0 \cdot 01$ \\
$1,2,3,7,8-P e C D D$ & $2 \cdot 7(<1-4 \cdot 6)$ & $5 \cdot 6(2 \cdot 7-10)$ & $0 \cdot 01$ \\
$1,2,3,4,7,8-H x C D D$ & 12 & $20(11-32)$ & $32(17-74)$ & $0 \cdot 04$ \\
$1,2,3,6,7,8-H x C D D$ & 13 & $4 \cdot 2(2 \cdot 1-5 \cdot 9)$ & $7 \cdot 3(3 \cdot 3-14)$ & $0 \cdot 02$ \\
$1,2,3,7,8,9-H x C D D$ & 14 & $51(26-113)$ & $46(29-75)$ & $0 \cdot 9$ \\
$1,2,3,4,6,7,8-H p C D D$ & 15 & $25(150-700)$ & $341(200-530)$ & $0 \cdot 7$ \\
OCDD & 16 & $25(17-42)$ & $60(27-190)$ & $0 \cdot 007$ \\
TCDD equivalents & & & & \\
\hline
\end{tabular}

${ }^{\star}$ Mann-Whitney $U$ test for comparison between groups (two tailed). ers and 38 in the control group. A general medical examination of all subjects did not show any clinical signs indicative of exposure to polychlorinated substances.

Blood samples were taken from the 19 people, who had been on a low fat diet for 12 hours. Standard hospital procedure was used in the separation of the blood plasma. The plasma bags were immediately frozen and stored at $-20^{\circ} \mathrm{C}$. All samples were coded before they were shipped to the analysing laboratory and were analysed blind. The samples were taken in late 1988 and analysed in early 1989.

\section{ANALYTICAL METHOD}

The analytical method for the determination of trace concentrations of PCDDs and PCDFs is described elsewhere. ${ }^{15}{ }^{16} \mathrm{In}$ short, the procedure involves extraction by means of organic solvents, cleaning up with various adsorbents, and a gravimetric determination of the lipid content. After cleaning up, the extracts were analysed by means of high resolution gas chromatography/high resolution mass spectrometry (HRGC/HRMS) techniques. The mass spectrometric data was obtained by means of a VG-250S high resolution MS operating in electron impact mode. In a quality control study between laboratories organised by the World Health Organisation, in which the concentration range was the same as that of the present study, this analytical method yielded an average coefficient of variation for reproducibility and repeatability of $6 \cdot 7 \% .{ }^{17}$

\section{STATISTICAL ANALYSIS}

Principal component analysis (PCA), described in detail by Wold et al, ${ }^{18}$ is a projection method in which the included variables are combined into a few underlying descriptive dimensions, which makes it possible to study the systematic variation present in a data matrix. The PCA gives an overview of the dominating patterns and major trends in the data. The analysis results in two complementary plots, a score plot and a loading plot. The relation between the objects (samples) is shown on the score plot. The loading plot shows the extent to which each variable contributes to the object separation. Variables located far from zero have a large influence. Cross validation ${ }^{19}$ was used to determine the number of significant principal components.

Differences between the two groups were also tested with non-parametric statistics (Mann-Whitney $U$ test)

\section{Results and discussion}

Table 1 shows the results of the analysis for PCDDs and PCDFs in blood plasma for nine of the workers (one worker was excluded for reasons accounted for later) and the control group, where the abbreviation $\mathrm{T}$ denotes tetra, Pe penta, Hx hexa, Hp hepta, and $O$ octa. Concentrations of PCDDs and PCDFs are expressed in $\mathrm{pg} / \mathrm{g}$ lipid extracted from the blood plasma. Also included are TCDD equivalents calculated according to the Nordic model, ${ }^{2}$ a model for risk assessment of com- 
plex mixtures of PCDDs and PCDFs.

The workers' concentrations of chlorinated PCDFs, primarily the $\mathrm{Hx}, \mathrm{Hp}$, and $\mathrm{O}$ chloro substituted PCDFs, are clearly raised, compared with the control group. The concentrations of some of the PCDD congeners are also increased, except for HpCDD and OCDD, and the Mann-Whitney U test shows a significant difference in TCDD equivalents between the two groups.

An unexpected result of the analysis was that low concentrations (4-17 pg/g lipid) of $1,2,3,4,6,8,9-\mathrm{HpCDF}$ were found in seven of the 10 workers. Isomers that are not $2,3,7,8-$ substituted are hardly ever detected in human samples. ${ }^{4}$

The mean sum of PCDFs for the workers and the control group was 583 and $85 \mathrm{pg} / \mathrm{g}$ lipid, respectively. There is a relation between the number of years in the production and concentrations of PCDFs. Figure 1 shows the ratio of $\Sigma$ PCDFs/ $\Sigma$ PCDDs plotted against years of employment at the plant. The ratio eliminates any age related increases in the concentrations of the congeners. ${ }^{20}$ The correlation coefficient $\left(r^{2}\right)$ was calculated to be 0.84 . The mean ratio of $\Sigma$ PCDFs/ $\Sigma$ PCDDs of the workers was $1 \cdot 1$ but the control group had a mean ratio of $0 \cdot 21$. In samples from people with no known occupational or accidental exposure, overall PCDD concentrations are normally much higher than PCDF concentrations.

The concentrations of the 16 detected $2,3,7,8$-substituted congeners in the blood samples were used as variables in the PCA. They were logarithmically transformed (table 1). Two principal components were significant and together they account for $82 \%(61+21)$ of the variance in the data set. As shown in the score plot (fig 2(A)), where the first principal component is plotted against the second, the workers and the controls form separate groups. The corresponding loading plot (fig

Figure 1 Years of employment plotted $v$ the ratio of IPCDF/IPCDDs.

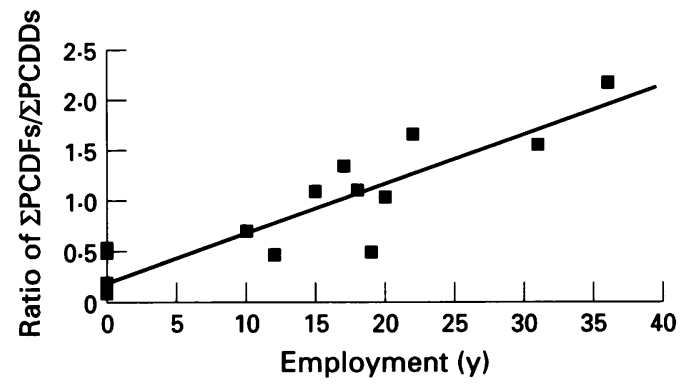

2(B)) shows that all congeners, except $1,2,3,4,6,7,8-\mathrm{HpCDD}$ (variable number 15) and OCDD (16) which are located close to zero, were to some extent active in this separation. The chlorinated dibenzofurans, $1,2,3,4,7,8$ and $1,2,3,6,7,8-\mathrm{HxCDF}$ (4 and 5), $1,2,3,4,6,7,8-\mathrm{HpCDF}$ (7) and particularly OCDF (9) contribute the most strongly to the separation of the groups. These isomers also account for the most significant difference between the two groups according to the Mann-Whitney $U$ test (table 1). The OCDF is a minor component (often not detected) in human samples. In this group of workers, the concentration of OCDF in the blood plasma was in the range of 17-560, with a mean of $216 \mathrm{pg} / \mathrm{g}$ lipid. These are unusually high concentrations in human samples and OCDF is undoubtedly the congener that most strongly correlates to occupational exposure in the magnesium plant. Analyses of indoor air from the plant show that OCDF accounts for $10 \%-40 \%$ of the total amount of PCDDs and PCDFs calculated as TCDD equivalents.

Studies have shown that crabs in this area contain very high concentrations of PCDFs and PCDDs ${ }^{10}$ and there are restrictions on the consumption of seafood from this area. The worker $A$ in the score plot, declared a very high consumption of crabs (50 crabs a year) from the coastal area near the magnesium plant. As we were not sure to what extent this high consumption of crabs reflects the concentrations of PCDFs and PCDDs in this person's blood plasma, he was excluded from table 1. Worker $\mathrm{A}$ has been with the company for 22 years and has primarily been doing maintenance work in the electrolytic sector. Table 2 shows the concentrations of PCDFs and PCDDs for worker $A$ and an additional person who also eats a lot of crabs from this area (a declared intake of 40 crabs a year) but who has no connection at all with the magnesium plant. The blood sample from this crab consumer was analysed in the same manner as the other samples but at a later time. His concentrations of several of the congeners are higher than the mean concentrations of both the workers and the control group, resulting in 101 TCDD equivalents in his blood fat. This indicates that a high consumption of crabs from this area may cause increased concentrations of PCDFs and PCDDs. The ratio of $\Sigma$ PCDFs// $\mathrm{PCDD}$ was 1.6 for worker A and 0.4 for the crab consumer. The higher ratio of worker A is likely to be caused by work related
Figure 2(A). The score plot of principal component $1 v$ principal component 2 from the 19 objects analysed. (B). Loading plot for the variables listed in table 1. The first loading vector is plotted $v$ the second.

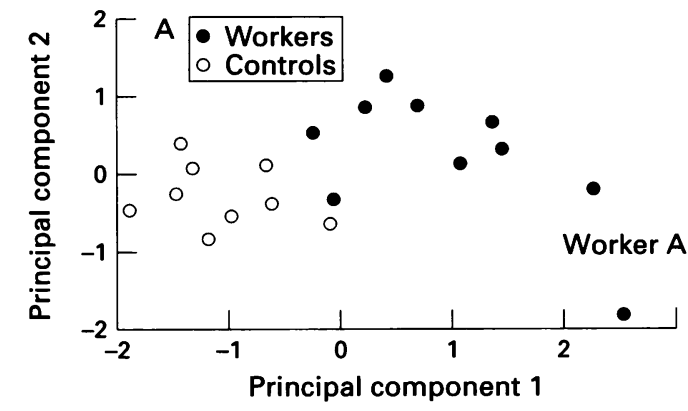


Table 2 Concentrations of PCDFs and PCDDs (pg/g lipid) in blood plasma from worker $A$ and a crab consumer

\begin{tabular}{lcc}
\hline & Worker $A$ & Crab consumer \\
\hline Crabs consumed (n/y) & 50 & 40 \\
PCDFs: & 11 & $2 \cdot 7$ \\
2,3,7,8-TCDF & 30 & $6 \cdot 5$ \\
1,2,3,7,8-PeCDF & 440 & 94 \\
$2,3,4,7,8-P e C D F$ & 400 & 99 \\
$1,2,3,4,7,8-H x C D F$ & 400 & 84 \\
$1,2,3,6,7,8-H x C D F$ & 20 & 11 \\
$2,3,4,6,7,8-H x C D F$ & 95 & 43 \\
$1,2,3,4,6,7,8-H p C D F$ & 7 & $<2$ \\
$1,2,3,4,7,8,9-H p C D F$ & 14 & $<3$ \\
OCDF & & \\
PCDDs: & 65 & 11 \\
$2,3,7,8-$ TCDD & 110 & 29 \\
$1,2,3,7,8-P e C D D$ & 26 & 13 \\
$1,2,3,4,7,8-H x C D D$ & 110 & 51 \\
$1,2,3,6,7,8-H x C D D$ & 26 & $6 \cdot 0$ \\
$1,2,3,7,8,9-H x C D D$ & 45 & 59 \\
$1,2,3,4,6,7,8-H p C D D$ & 480 & 620 \\
OCDD & 442 & 101 \\
TCDD equivalents &
\end{tabular}

exposure to PCDFs. It is not possible to establish whether worker A's overall increased concentrations (442 TCDD equivalents) were due to the working environment or to a high consumption of crabs as our numbers were too small for any conclusions to be drawn. It is likely that the high concentrations of PCDFs and PCDDs in the blood lipids are attributable to both of these factors. The consumption of contaminated marine biota is believed to play a substantial part in human concentrations of PCDDs and PCDFs, as has been shown by Svensson et al. ${ }^{21}$ They found significantly higher concentrations of PCDDs and PCDFs in men with a high intake of fish from the Baltic Sea than in men who consumed less or no fish. An ongoing study of consumers of crabs from the Norwegian coast, performed by the National Institute of Public Health in Norway, will hopefully provide further information.

In two other studies of occupational exposure to PCDDs and PCDFs in a metal reclamation plant ${ }^{7}$ and a municipal waste incinerator, ${ }^{22}$ higher blood concentrations of PCDFs were found in the workers compared with control groups. In both cases the $\mathrm{Pe}, \mathrm{Hx}$, and $\mathrm{HpCDF}$ concentrations were raised but the high concentrations of OCDF found in the workers in the magnesium plant were not detected.

\section{Conclusion}

Blood samples provide an index of past cumulative exposure to PCDDs and PCDFs, due to the long biological half lives and lipid solubility of these compounds. People exposed accidentally or occupationally often have a different congener pattern than those exposed indirectly through the environment and such exposure can be identified through the analysis of PCDDs and PCDFs in blood.

This report presents findings of increased concentrations of PCDFs and PCDDs in the blood plasma from workers in a magnesium production plant. The dominating congeners in these workers, compared with the control group, are $1,2,3,4,7,8-$ and $1,2,3,6,7,8-$ $\mathrm{HxCDF}, 1,2,3,4,6,7,8-\mathrm{HpCDF}$ and, in particular, OCDF. A non-2,3,7,8-substituted congener, $1,2,3,4,6,8,9-\mathrm{HpCDF}$, was also identified in seven of the 10 workers. A comparison of the ratio of $\Sigma P C D F / \Sigma P C D D s$ shows that the predominance of the $\Sigma$ PCDFs over $\Sigma$ PCDDs correlates with years of employment in the magnesium plant.

The present study shows that a combination of isomer specific analysis and principal component analysis provides a means of characterising different kinds of occupational exposure.

We are indebted to Professor Erik Dybing at the National Institute of Public Health, Department of Environmental Medicine, Oslo, Norway and Professor Ulf Ahlborg at the Institute of Environmental Medicine, Karolinska Institute, Stockholm, Sweden for fruitful discussions and constructive criticism.

1 Van den Berg M, De Jongh J, Poiger $\mathrm{H}$, Olson J R. The toxicokinetics and metabolism of polychlorinated dibenzo-p-dioxins (PCDDs) and dibenzofurans (PCDFs) and their relevance for toxicity. Crit Rev Toxicol 1994;24:1-74.

2 Ahlborg UG, Brouwer A, Fingerhut MA, Jacobsen $\mathrm{JL}$, Jacobsen SW, Kennedy SW, et al. Impact of polychlorinated dibenzo-p-dioxins, dibenzofurans and biphenyls on human and environmental health, with special emphasis on application of toxic equivalency factor concept. Eur $\mathcal{F}$ Pharmacol 1992;228:179-99.

3 Rappe C. Sources of exposure, environmental concentrations and exposure assessment of PCDDs and PCDFs. Chemosphere 1993;27:221-5.

4 Ryan JJ, Norstrom RJ. Occurrence of polychlorinated dibenzo-p-dioxins and dibenzofurans in humans and major exposure routes. LARC Sci Publ 1991;108:51-104

5 Patterson DG, Fingerhut MA, Roberts DW, Needham LL Sweeney MH, Marlow DA, et al. Levels of polychlorinated dibenzo-p-dioxins and dibenzofurans in workers exposed to $2,3,7,8$-tetrachloradibenzo-p-dioxin. $A m \mathcal{J}$ Ind Med 1989;16:135-46.

6 Littorin M, Hansson M, Rappe C, Kogevinas M. Dioxins in blood from Swedish phenoxy herbicide workers. Lancet 1994;344:611-2.

7 Päpke O, Ball M, Lis A. Various PCDD/PCDF patterns in human blood resulting from different occupational exposures. Chemosphere 1992;25:1101-8.

8 Fiedler H, Hutzinger O, Timms CW. Dioxins: source of environmental load and human exposure. Toxicology and Environmental Chemistry 1990;29:157-234.

9 Oehme M, Mano S, Bjerke B. Formation of polychlorinated dibenzofurans and dibenzo-p-dioxins by production processes for magnesium and refined nickel. Chemosphere 1989;18:1379-89.

10 Oehme M, Mano S, Brevik EM, Knutzen J. Determination of polychlorinated dibenzofurans (PCDF) and dibenzop-dioxins (PCDD) levels and isomer patterns in fish crustacea mussels and sediment samples from a fiord region polluted by $\mathrm{Mg}$-production. Fresenius $Z$ Anal Chem 1989;335:987-97.

11 Oehme M, Bartonova A, Knutzen J. Estimation of polychlorinated dibenzofuran and dibenzo-p-dioxin contamichlorinated dibenzofuran and dibenzo-p-dioxin contamination of a coastal region using isomer profiles in crat
Environmental Science Technology 1990;24:1836-41.

12 Knutzen J, Oehme M. Polychlorinated dibenzofuran (PCDF) and dibenzo-p-dioxins (PCDD) levels in organisms and sediment from the Friefjord, southern Norway. Chemosphere 1989;19:1897-909.

13 Clench-Aas J, Bartonova A, Oehme M, Linström G. PCDD and PCDF in human milk from Scandinavia, with special emphasis on Norway. I Toxicol Environ Health 1992;37:73-83.

14 Heldaas S, Langård S, Andersen A. Incidence of cancer in a cohort of magnesium production workers. $\mathrm{Br} ₹$ Ind $\mathrm{Med}$ cohort of magnesiun

15 Nygren $M$, Hansson $M$, Sjöström $M$, Rappe C, Kahn P, Gochfeld M. et al. Development and validation of a method for determination of PCDDs and PCDFs in human blood plasma. Chemosphere 1988;17:1663-93.

16 Kahn P, Gochfeld M, Nygren M, Hansson M, Rappe C Velez $\mathrm{H}$, et al. Dioxins and dibenzofurans in blood and dipose tissue of agent orange exposed Vietnam veteran and matched controls. $\mathscr{F} A M A$ 1988;259:1661-7.

17 WHO/EURO. Levels of PCBs, PCDDs and PCDFs in human milk and blood. Second round of quality control Environment and Health in Europe 37. Copenhagen: FADL, 1991.

18 Wold S, Esbensen K, Geladi P. Principal component analysis. Chemometrics and Intelligent Laboratory Systems 1987;2:37-52.

19 Wold S. Cross-validatory estimation of the number of components in factor and principal components models. ponents in factor and princip

20 EPA. Chlorinated dioxins and furans in the general population: NHATS FY 87 results. Washington, DC: Office of Toxic Substances 1991. (EPA-560/5-91-003.)

21 Svensson B-G, Nilsson A, Hansson M, Rappe C, Åkesson B, Skerfving S. Exposure of dioxins and dibenzofuran through the consumption of fish. $N$ Engl f Med 1991; 324:8-12.

22 Päpke O, Ball M, Lis A. Potential occupational exposure of municipal waste incinerator workers with $\mathrm{PCDD} / \mathrm{PCDF}$. Chemosphere 1993;27:203-9. 